\title{
Tetrapropylammonium-manganese oxide/polypyrrole hybrid nanocomposite thin films as novel electrode materials for supercapacitors
}

\author{
Suk Fun Chin*, Suh Cem Pang \\ Department of Chemistry, Faculty of Resource Science and Technology, Universiti Malaysia Sarawak (UNIMAS), 94300, Kota Samarahan, Sarawak, Malaysia
}

\section{A R T I C L E I N F O}

\section{Article history:}

Received 30 October 2009

Received in revised form 25 May 2010

Accepted 25 June 2010

\section{Keywords:}

Hybrid nanocomposites

Thin films

Heat treatment

Electrochemical properties

\section{Introduction}

Manganese oxides in their various forms have been extensively studied and developed as electrode materials in supercapacitors [1-3]. Manganese oxide-based materials received particular attention and interest due to the low cost of raw materials, low toxicity and superior electrochemical performances. Our earlier studies have shown that tetrapropylammonium-manganese oxide (TPAMO) thin films are promising electrode materials for the fabrication of thin film supercapacitors due to their high specific capacitance, good cycling reversibility and stability [1]. However, the major drawback of manganese oxide is its low electronic conductivity. Carbon powder such as acetylene black is generally being added to manganese oxides to improve their conductivities. However, such addition of materials without electrochemical activity tends to reduce the overall energy density of these electrode materials [4].

Recently, conducting polymers such as polypyrrole and polyaniline have been studied extensively as active electrode materials for supercapacitors due to their relatively high electronic conductivities and reversible redox reactions $[5,6]$. Although conducting polymers possess high conductivity, the brittleness, poor environmental stability and poor charge-discharge characteristics of these materials have hampered their widespread applications in such electrochemical devices. Several researchers have attempted to synthesize manganese dioxide/polypyrrole $\left(\mathrm{MnO}_{2} / \mathrm{Ppy}\right)$ nanocom-

\footnotetext{
* Corresponding author. Tel.: +60 82 582999; fax: +60 82583160.

E-mail address: sfchin@frst.unimas.my (S.F. Chin)
}

posite since the synergetic interaction of $\mathrm{MnO}_{2}$ and Ppy would enhance the electrochemical performance and mechanical stability of the electrode. Sharma et al. have used electrochemical deposition method to prepare $\mathrm{MnO}_{2} / \mathrm{Ppy}$ nanocomposite. In their studies, polypyrrole was being used as the support for the deposition of manganese oxide. A specific capacitance value as high as $600 \mathrm{Fg}^{-1}$ was achieved for their $\mathrm{MnO}_{2} / \mathrm{Ppy}$ thin film electrodes [7]. Carbon nanotube (CNT) supported $\mathrm{MnO}_{2} /$ Ppy has been synthesized by the chemical synthesis method in order to improve the dispersibility and surface area of $\mathrm{MnO}_{2} / \mathrm{Ppy}[8,9]$. However, much lower specific capacitance values of 268 and $281 \mathrm{~F} \mathrm{~g}^{-1}$ were reported. The high specific capacitance observed in $\mathrm{MnO}_{2}$ based electrode materials are mainly attributed to the pseudocapacitance arising from redox processes. The CNT in electrode materials did not contribute positively to the pseudocapacitance and hence resulted in decreased specific capacitance value for these $\mathrm{CNT} / \mathrm{MnO}_{2} / \mathrm{Ppy}$ electrode materials.

In this paper, we have reported on the synthesis of tetrapropylammonium-manganese oxide/polypyrrole (TPAMO/Ppy) hybrid nanocomposite by a combination of in situ polymerization and sol-gel processes. In contrast to previous studies as reported in the literatures which produced spherical shaped $\mathrm{MnO}_{2}$ /Ppy nanocomposites [7-9], our synthesis approach has resulted in fibrous $\mathrm{MnO}_{2} / \mathrm{Ppy}$ nanocomposite. Such fibrous structures had been demonstrated to be the more favorable morphology of electrode materials by providing short diffusion path-lengths for ions and excitons thereby giving rise to high charge-discharge rates. Furthermore, fibrous structures reduce the diffusion resistance of electrolytes during rapid charge-discharge 